\title{
REVIEW
}

\section{Primary hyperparathyroidism: diagnosis and management in the older individual}

\author{
$\mathrm{S}_{\text {Boonen }}^{1,2,3}$, D Vanderschueren ${ }^{2,3,4}$, W Pelemans ${ }^{1,2}$ and R Bouillon ${ }^{2,3,4}$ \\ ${ }^{1}$ Division of Geriatric Medicine, ${ }^{2}$ Center for Metabolic Bone Diseases, ${ }^{3}$ Laboratory for Experimental Medicine and Endocrinology and \\ ${ }^{4}$ Division of Endocrinology, Katholieke Universiteit Leuven, Leuven, Belgium
}

(Correspondence should be addressed to S Boonen, Leuven University Center for Metabolic Bone Diseases and Division of Geriatric Medicine, Universitaire Ziekenhuizen KU Leuven, Herestraat 49, B-3000 Leuven, Belgium; Email: steven.boonen@uz.kuleuven.ac.be)

\begin{abstract}
As more and more cases of primary hyperparathyroidism are being detected by screening for serum calcium concentration, the majority of patients are older individuals who are asymptomatic or have symptoms which are difficult to ascribe to hyperparathyroidism. Long-term follow-up has provided evidence that most asymptomatic patients who do not undergo parathyroidectomy will not develop symptomatic complications. Some asymptomatic patients, however, have progression of disease over time. These observations and the lack of reliable predictors of the rate of progression in most patients reinforce the need for careful monitoring in elderly individuals who do not undergo surgery. Biannual measurements of serum calcium concentrations and annual measurements of urinary calcium excretion and bone mineral density should be performed in all patients who are managed conservatively. In elderly patients with symptomatic or complicated primary hyperparathyroidism, parathyroidectomy results in biochemical cure and increased bone density, both at the lumbar spine and the femoral neck, and should be considered. Criteria for surgery include significant hypercalcemia ( $>1 \mathrm{mg} / \mathrm{dl}$ above the upper limit of normal), marked hypercalciuria ( $>400 \mathrm{mg}$ per day), low bone density, unexplained renal insufficiency and an episode of acute primary hyperparathyroidism. Consideration of parathyroidectomy should also be given to elderly patients with primary hyperparathyroidism who are vitamin D deficient. Radionuclide scanning has become the initial non-invasive study of choice when parathyroid gland localization is necessary before parathyroidectomy; this is generally for fragile patients and reoperative cases. In a subset of older individuals, surgery may not be an option because of coexisting medical problems even though surgical indications are present.
\end{abstract}

European Journal of Endocrinology 151 297-304

\section{Introduction}

Primary hyperparathyroidism is a hypercalcemic state due to excessive secretion of parathyroid hormone (PTH) (1-3). The disease is characterized by a loss of the normal feedback control of PTH by extracellular calcium, but the exact underlying cause remains to be clarified (4). In most patients, a benign, solitary adenoma is responsible for the hypersecretion. Primary hyperparathyroidism due to parathyroid hyperplasia is less common and may occur in the context of the syndrome of multiple endocrine neoplasia (which will not be discussed in this review). The incidence of the disease is from about 1 in 500 to 1 in 1000. The majority of individuals affected by primary hyperparathyroidism are older women. In most patients, hypercalcemia is discovered when serum calcium is measured as a screening test. Primary hyperparathyroidism is one of the most common causes of hypercalcemia and should be considered in any elderly individual with elevated serum calcium level. Unless another cause of the hypercalcemia is obvious - for example, the patient is known to have metastatic bone disease - the first step is measurement of serum PTH. A high or even inappropriately normal value in the presence of hypercalcemia confirms the diagnosis. There are a few diagnostic pitfalls: some patients have both hyperparathyroidism and another hypercalcemic disorder; others are taking a thiazide or lithium carbonate, which can exacerbate or perhaps even cause hyperparathyroidism; and a few have benign familial hypercalcemia, in which a loss-of-function mutation in the calcium-receptor gene causes increased PTH secretion and hypocalciuria. These disorders can be distinguished from primary hyperparathyroidism by careful history taking and measurements of urinary calcium. The aim of this review is to discuss the diagnosis and management of primary hyperparathyroidism in elderly patients ('elderly' being defined as 75 years of age or older). 


\section{Clinical presentation of primary hyperparathyroidism}

Primary hyperparathyroidism has evolved from a symptomatic disorder to a disorder that is asymptomatic in most patients $(1,5)$, including patients over the age of 70 years (6). In most older individuals with asymptomatic primary hyperparathyroidism, serum calcium levels are less than $1 \mathrm{mg} / \mathrm{dl}$ above the accepted normal reference range. These individuals have neither signs nor symptoms typically associated with hypercalcemia or PTH excess. Older patients may present with serum calcium levels in the lifethreatening range, the so-called acute primary hyperparathyroidism or parathyroid crisis (2), but this is unusual.

Subperiosteal resorption and bone cysts, a skeletal complication known as osteitis fibrosa cystica, has become most unusual in patients with primary hyperparathyroidism, even in elderly individuals. However, primary hyperparathyroidism is typically characterized by various degrees of bone loss. Previous reports have clarified that cortical and trabecular bone are affected in different ways by excess of PTH (5). Histomorphometric studies of percutaneous bone biopsy specimens in patients with primary hyperparathyroidism have shown a preferential involvement of cortical bone with a relative preservation of cancellous bone (7). According to these findings, bone densitometry in these patients has shown a greater and more precocious bone loss at the appendicular skeleton, which is mainly comprised of cortical bone, than at the axial skeleton, where trabecular bone predominates $(8,9)$. Whether PTH-related bone loss is associated with an increased fracture risk remains unclear. A number of retrospective and case-control studies have not shown an increase in fracture incidence among patients with primary hyperparathyroidism (10-12), whereas others have (13-15). These studies are limited by their cross-sectional design, inadequate control groups, ascertainment biases and imprecise definitions of fracture. There clearly is a need for large, prospective, controlled studies to evaluate fracture incidence in primary hyperparathyroidism, particularly in older individuals. It has been well established that, besides bone density, other factors such as the risk of falling play a critical role in determining susceptibility to fracture in old age.

Nephrolithiasis is the most frequent complication of the hyperparathyroid process, occurring in about $20 \%$ of the patients (16). Renal effects of the disease also include diminished glomerular filtration rate. Since renal function tends to decline with age, it is likely that most older individuals with hyperparathyroidism will have at least some degree of renal insufficiency. Hypercalciuria ( $>300 \mathrm{mg}$ daily calcium excretion) is observed in a significant subset (of up to 30\%) of patients. Some patients suffer from easy fatigability, a sense of weakness and mild cognitive impairment (17). Whether these non-specific symptoms are indeed related to hyperparathyroidism remains to be clarified, especially in old age (18). The extent to which they respond to parathyroid surgery has not yet been settled either. Finally, the association of primary hyperparathyroidism with hypertension has been well documented but poorly understood (19). Parathyroidectomy does not reliably improve hypertension in these patients, and it is not clear whether surgery alters the long-term course of their hypertension.

\section{Evaluation of older patients with primary hyperparathyroidism}

Hypercalcemia is virtually always present in patients with primary hyperparathyroidism, while serum phosphorus tends to be in the lower range of normal. In some patients - particularly those with mild primary hyperparathyroidism - serum calcium may be normal on some measurements. In elderly patients, all calcium concentrations should be 'corrected' to the prevailing serum albumin level (calcium to be adjusted upwards by $0.8 \mathrm{mg} / \mathrm{dl}$ for every $\mathrm{g} / \mathrm{dl}$ reduction in serum albumin from the midnormal range of $4.0 \mathrm{~g} / \mathrm{dl})$. The most common other cause of hypercalcemia in older individuals, hypercalcemia of malignancy, is associated with suppressed levels of PTH. Therefore, an elevated level of PTH in the presence of hypercalcemia virtually establishes the diagnosis of primary hyperparathyroidism, although the normal range for the PTH-intact assay (generally $10-65 \mathrm{pg} / \mathrm{ml}$ ) does not take into account the fact that PTH levels rise with age. Serum alkaline phosphatase activity may be elevated. Increased bone turnover may be reflected in elevated levels of markers of bone formation (bone-specific alkaline phosphatase and osteocalcin) and bone resorption (urinary pyridinoline, deoxypyridinoline and N-telopeptide of collagen), even in the absence of skeletal complications (2). However, bone markers increase with age, and it is not clear that elevated levels of bone markers are predictive of the likelihood of bone loss and fractures in older individuals with primary hyperparathyroidism. Urinary calcium excretion may be elevated as well, but this varies widely and is often not increased in elderly patients. While the circulating 1,25-dihydroxyvitamin D concentration may be elevated, levels of 25-hydroxyvitamin $\mathrm{D}$ tend to be low or in the lower range of normal in older individuals.

In most older patients, no specific radiological manifestations are observed, and skeletal x-ray screening is not recommended. However, bone-density measurements - based on dual-energy x-ray absorptiometry (DXA) at the hip and spine - should be an integral part of the evaluation of individuals with primary hyperparathyroidism, regardless of age. As indicated, 
the disease preferentially affects the cortical as opposed to the trabecular skeleton. This pattern of bone involvement is typically reflected in reduced DXA values at the femoral neck (a site enriched in cortical bone) and relative preservation of the trochanter and lumbar spine (sites primarily consisting of cancellous bone).

\section{Management of primary hyperparathyroidism - treating older patients surgically}

Irrespective of age, surgery is recognized as the only definitive therapy for primary hyperparathyroidism, and patients with symptomatic hyperparathyroidism or documented complications should always be considered for parathyroidectomy. However, a large subgroup of older patients who are asymptomatic are unlikely to develop complications of the disease and may not need surgery. In order to target surgery on those among the asymptomatic who are most at risk of complications of this disease, a set of guidelines is used, as originally recommended by a Consensus Development Conference on the Management of Asymptomatic Primary Hyperparathyroidism, held in 1990 at the National Institutes of Health (20). According to these guidelines, surgery is recommended as the primary option in (i) those with a serum calcium more than $1 \mathrm{mg} / \mathrm{dl}$ above the upper limit of normal, (ii) those with any complication of primary hyperparathyroidism (such as overt bone disease or nephrolithiasis), (iii) patients with an episode of acute primary hyperparathyroidism with life-threatening hypercalcemia, (iv) patients with marked hypercalciuria (more than $400 \mathrm{mg}$ daily excretion) and, finally, (v) those with a reduction in bone density (Table 1). Although these guidelines were not intended to provide specific recommendations for geriatric patients, the majority of older individuals with primary hyperparathyroidism will meet at least one of these criteria despite being asymptomatic - and should be considered (potential) candidates for surgery. For example, marked

Table 1 Criteria to consider surgery in elderly patients with primary hyperparathyroidism.

1. Serum calcium more than $1 \mathrm{mg} / \mathrm{dl}(0.25 \mathrm{mM})$ above the upper limit of normal

2. Any complication of primary hyperparathyroidism (e.g., overt bone disease, nephrolithiasis)

3. An episode of acute primary hyperparathyroidism with lifethreatening hypercalcemia

4. Marked hypercalciuria (more than $400 \mathrm{mg}$ daily excretion)

5. Osteoporosis (reduction in bone density of more than 2.5 standard deviations below peak bone mass), as determined by DXA at the lumbar spine, total hip or femoral neck

6. Worsening hypercalcemia and/or calciuria or decreasing bone density over time

7. Primary hyperparathyroidism associated with vitamin $D$ deficiency hypercalciuria or reduced bone density occurs not infrequently in asymptomatic hyperparathyroidism.

More recently, the conclusions of the 1990 Consensus Development Conference have been re-evaluated (3), and additional groups of patients have been recognized who may benefit from parathyroidectomy. Individuals who have low vertebral or femoral neck bone density - as determined by DXA - constitute such a group (21). In the original 1990 consensus, low bone density was defined as a density of more than two standard deviations below age- and sex-matched control subjects, as assessed by single-photon absorptiometry (SPA) at the distal radius. However, over the past decade, DXA has become the key instrument in the measurement of bone mass because of its accuracy and precision, and because it allows the evaluation of bone density at the spine and the hip, the sites of major clinical interest. Regardless of age, osteoporosis (in women) is currently defined by the WHO as a DXA T-score below -2.5 , that is, a bone density of more than 2.5 SDS below peak bone density (22). It has been assumed, but not established, that reduction in bone density in primary hyperparathyroidism predicts fracture risk to the same extent as reductions in density predict fracture risk in populations without primary hyperparathyroidism. Therefore, recent recommendations suggest surgery if the T-score at the lumbar spine or hip (or distal radius) is below -2.5 (3), a threshold consistent with the WHO definition of osteoporosis.

Significant advances in surgery, particularly minimally invasive approaches, have been made. In older patients, the operation is being performed increasingly under local anaesthesia (23). Because PTH is cleared from the circulation within minutes, intraoperative PTH assays indicate whether the patient has been cured or additional exploration is needed (24). Specifically, serum PTH concentrations fall by $50 \%$ or more after parathyroid adenomas are removed, and when that occurs, virtually all patients become normocalcemic. In many patients, the exploration, resection and testing can be done as an outpatient procedure.

A number of preoperative localization procedures have been developed to identify the site of abnormal parathyroid tissue preoperatively, including ultrasound, computed tomography, magnetic resonance imaging and scintigraphy (25-30). Scintigraphy with technetium-99 sestamibi has emerged as the most sensitive and most convenient to perform (31-33). However, even with sestamibi scanning, there is a significant incidence of false-positive findings, so that confirmation with two approaches - for example, complementary parathyroid scintigraphy and high-resolution ultrasonography - is recommended for accurate localization $(34-36)$.

In older patients who have had prior neck surgery, most surgeons would agree that preoperative localization is extremely helpful, even to the expert parathyroid 
surgeon. However, the use of sestamibi imaging cannot be uniformly recommended in patients without prior neck surgery. In the hands of an experienced surgeon, successful parathyroid surgery can be expected $95 \%$ of the time in patients who have not had previous neck surgery $(5,37)$. In these patients, there is no evidence that operative time is reduced or that the complication frequency decreased, or even that the success rate of parathyroid surgery is greater with preoperative imaging $(38,39)$.

Following parathyroid surgery, serum calcium normalizes and the PTH level returns to normal. It is unusual for the patient to experience a postoperative period of symptomatic hypocalcemia. Over time, bone turnover decreases markedly, as judged by both biochemical markers and histomorphometric measurements (40). At the same time, bone density increases. Recent long-term data on the course of treated and untreated asymptomatic primary hyperparathyroidism have confirmed that successful surgery leads to sustained increases in bone mineral density at sites rich in cancellous bone such as the lumbar spine, where a mean rise of $12 \%$ in bone mass is seen after parathyroidectomy $(8,21$, $41,42)$. In line with this increase in bone density, there is preliminary (case-control) evidence to suggest that surgery might reduce the risk of subsequent fracture (43). A satisfactory explanation for the sustained increase in bone density after parathyroidectomy remains elusive. One hypothesis attributes the increase to mineralization of the expanded remodelling space that is characteristic of primary hyperparathyroidism (44). This hypothesis, however, does not explain why the increase in bone density is sustained. Alternatively, surgery might restore normal pulsatility to the secretion of PTH, which is thought to stimulate the formation of cancellous bone $(45,46)$. Paradoxically, although cortical bone is more vulnerable than cancellous bone to the catabolic effects of PTH, parathyroidectomy is not followed by an increase in radial bone density. Prospective observations have clearly indicated that cortical bone loss in patients with primary hyperparathyroidism is not readily reversible $(8,41)$.

\section{Management of primary hyperparathyroidism - medical treatment alternatives}

Patients who are not considered for parathyroid surgery should remain well hydrated and avoid immobilization $(20,47)$. Particularly in older individuals, prompt medical attention for the possibility of worsening hypercalcemia is urged in the event of any serious intercurrent illness accompanied by risk of dehydration. Thiazide diuretics may increase hypercalcemia and should not be prescribed. A moderate dietary calcium intake is recommended (48), although it remains unknown to what extent fluctuations in serum calcium in patients with primary hyperparathyroidism are a function of dietary calcium intake. Medical follow-up usually includes visits twice yearly with determinations of serum calcium and urinary calcium excretion. Yearly bone densitometry is also recommended (20).

Effective therapeutic agents for the long-term medical management of primary hyperparathyroidism are not available yet. The use of oral phosphate has been limited by its lack of efficacy, risk of metastatic calcification and gastrointestinal intolerance (47). Oestrogen therapy reduces PTH-mediated bone resorption (49, 50 ), but it is not a treatment option in older women because of its side effects and because it has little effect on serum levels of calcium and PTH. There are no data on the effectiveness of selective oestrogen receptor modulators (such as raloxifene) on serum calcium or PTH levels in this disorder. Bisphosphonates also have been considered as a possible medical approach to primary hyperparathyroidism. Etidronate and clodronate do not result in sustained suppression of disease activity $(51,52)$. Recent data support the use of the more potent bisphophonates alendronate or risedronate in the management of the disease, particularly in elderly patients with other co-morbidities rendering them at increased surgical risk. Long-term data on antiresorptive treatment and fracture risk in primary hyperparathyroidism are not available, but both bisphosphonates have shown short-term efficacy on surrogate markers such as serum calcium and bone density (53-55). Compared with risedronate, alendronate has been the subject of more intensive investigation. In older women with primary hyperparathyroidism, alendronate is well tolerated, reduces bone turnover and significantly improves bone density at the lumbar spine (with lesser gains at the femoral neck and radius), especially within the first year of treatment. Serum calcium may be moderately reduced during treatment, but there is insufficient evidence to support the use of alendronate or risedronate for normalization of calcium in older patients with primary hyperparathyroidism. Reassuringly, alendronate studies in elderly individuals have shown no increase in PTH levels. A more targeted approach to the medical therapy of primary hyperparathyroidism would be to interfere specifically with the production of PTH. A new class of agents, termed calcimimetics, alter the function of the extracellular calcium-sensing receptor and are currently undergoing clinical research in patients with primary hyperparathyroidism (56).

The rate of progression of hyperparathyroidism is slow. Indeed, patients with asymptomatic primary hyperparathyroidism who are not surgical candidates for parathyroidectomy appear to do well when they are managed conservatively $(9,41,57)$. They are unlikely to develop symptomatic complications such as fractures or kidney stones, but long-term data on physical and neuropsychological symptoms are not available. In general, they do not show substantial 
changes in serum or urinary indices or in bone density, not even during long-term follow-up periods of up to 10 years (41). The inability to detect decreases in bone density in most older patients who did not undergo parathyroidectomy could be related to the presence of vertebral degenerative joint diseases, which can alter bone density values at the lumbar spine, but the finding that femoral-neck bone density also remains stable makes this explanation unlikely. It is tempting to speculate that patients with primary hyperparathyroidism are partially protected against the expected age-related bone loss, perhaps because of the continued anabolic effect of PTH on cancellous bone $(45,46)$. Long-term epidemiological data also indicate that these patients do well with respect to morbid and fatal events (58). Their long-term survival is not adversely affected (21).

Bone density, however, is not stable in all asymptomatic patients. About 25\% of the patients with asymptomatic primary hyperparathyroidism have progression, defined as the development of at least one new indication for parathyroidectomy, including worsening hypercalcemia or decreasing bone density (41). Although it remains to be clarified to what extent PTH-related bone loss is associated with increased fracture risk, these findings and the absence of reliable predictors of bone loss in most patients (59) make regular measurement of bone density mandatory in those who do not undergo parathyroidectomy.

There is some ongoing therapeutic controversy as to whether parathyroidectomy should generally be recommended for all patients with primary hyperparathyroidism, even in the absence of symptoms or complications $(21,60,61)$. Some authors argue that the time and expense involved in rigorous follow-up would outweigh the burden of surgery. Since the 1990 consensus concluded that there are categories of patients (over the age of 50 years) who can be safely followed without surgery, that view has been challenged and reports favouring surgery in all patients have appeared. However, most authors still hold the view that patients without symptoms or complications may be expected to do well with long-term conservative management without surgery.

\section{Management of primary hyperparathyroidism - a geriatric perspective (Fig. 1)}

Clearly, many issues remain unsettled, and controlled, prospective, randomized studies are needed to provide greater confidence in making recommendations concerning management of primary hyperparathyroidism

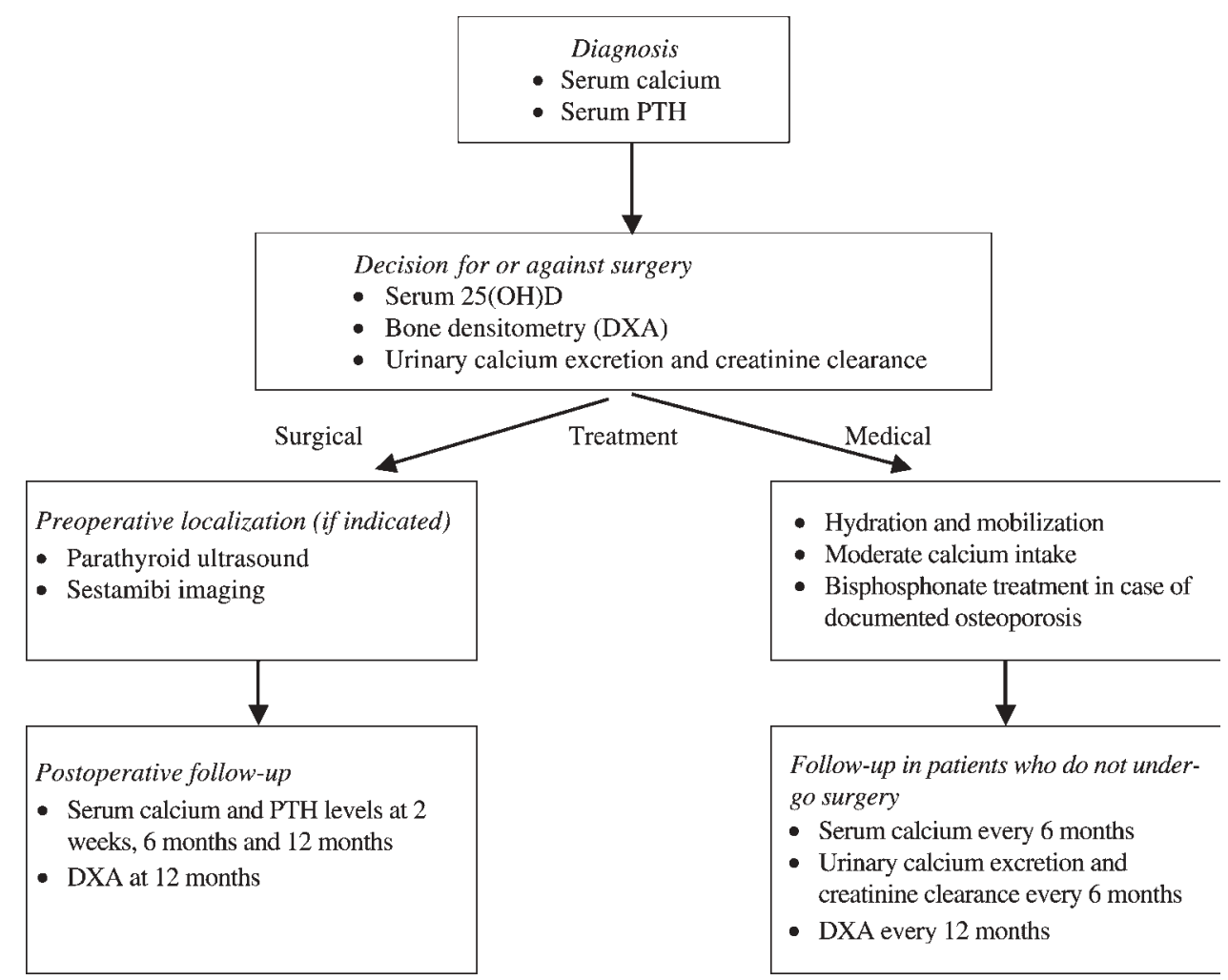

Figure 1 Diagnosis and management of primary hyperparathyroidism: decisional flow chart from a geriatric perspective. $\mathrm{PTH}$, parathyroid hormone; 25(OH)D, 25-hydroxyvitamin D. 
in old and very old individuals. The majority of elderly patients with primary hyperparathyroidism present with mild elevations of the serum calcium concentration without overt symptoms (6). Although our knowledge remains incomplete, there is increasing evidence that the rate of progression of hyperparathyroidism in these patients is slow, and that it is safe to follow them and to manage their mild disease medically. In a recent population-based study, there was no evidence that primary hyperparathyroidism with mild hypercalcemia has any adverse effect on survival (58). Nevertheless, some authors recommend parathyroidectomy in all patients, in part because the operative mortality is extremely low (62), and in part because of reports suggesting that surgery may prevent fractures even in mildly hypercalcemic patients (43) and data suggesting surgical reduction of increased long-term mortality risk (63). We support the view that although parathyroidectomy remains the only definitive therapy for primary hyperparathyroidism, surgical intervention is not necessary in all patients $(21,64)$. Particularly in old age, it does not seem appropriate to take a potential reduction of long-term mortality by parathyroidectomy into account when deciding for or against surgery.

While it seems reasonable to adopt a conservative policy in the elderly asymptomatic patient, parathyroidectomy remains the appropriate therapy for symptomatic or complicated primary hyperparathyroidism, even in old age. Consideration of parathyroidectomy should also be given to elderly patients with primary hyperparathyroidism who are vitamin D deficient (21). Vitamin D deficiency may be associated with a worsening of primary hyperparathyroidism due to loss of the regulatory effects of 1,25-dihydroxyvitamin D on the PTH gene. Efforts to correct this deficiency by vitamin D replacement in the face of hypercalcemia and/or hypercalciuria can be risky. Parathyroidectomy may be a more appropriate alternative in such cases (Table 1). There appear to be no differences in complication rate or symptom relief associated with surgery between younger and older patients (65). Guidelines for surgery, however, may not exclusively influence decisions for or against parathyroidectomy. Elderly patients with coexisting medical problems may not be candidates for surgery even though surgical indications are present. In older patients with documented osteoporosis who have a high surgical risk, bisphosphonate treatment should be considered to improve (trabecular) bone quality, and it may even have a role in stabilizing a modest degree of hypercalcemia. Since bisphosphonates are eliminated almost exclusively by the kidney, they may accumulate in older patients with compromised renal function; before initiating treatment, creatinine clearance should be assessed. Because alendronate, an aminobisphosphonate, is associated with a significant risk of oesophagitis (66), risedronate is a more attractive treatment option (67).
Whether patients without prior neck surgery should undergo preoperative localization procedures remains a controversial issue, regardless of their age. Nevertheless, attempts to localize the parathyroids may be particularly helpful in frail elderly patients who would otherwise not be candidates for surgery. Indeed, some elderly patients can be explored under local anesthesia if they have had successful preoperative localization of the adenoma.

\section{Conclusion}

The clinical presentation of primary hyperparathyroidism has dramatically changed over the past decades, and now the disease typically affects elderly women and is characterized by mild hypercalcemia and few symptoms or complications. It would seem that the overall population of older patients with mild asymptomatic primary hyperparathyroidism can be safely followed without intervention. A certain proportion of cases do progress, however, so surveillance is necessary. Individual patients can have worsening hypercalcemia or hypercalciuria, and in a small percentage of patients, bone density may decrease over time. In most patients, deferral of surgery is not a one-time decision, but rather one that is reviewed and reconsidered in conjunction with meticulous monitoring. All patients should be evaluated at least twice yearly, including serum calcium levels. Urinary calcium excretion and bone mineral density should be assessed annually.

\section{Acknowledgements}

Dr S Boonen and Dr D Vanderschueren are both Senior Clinical Investigators for the Fund for Scientific Research-Flanders (F.W.O.-Vlaanderen). Dr Boonen holds the Leuven University Chair for Metabolic Bone Diseases. This work was supported by grant G.0171.03 from the Fund for Scientific Research-Flanders, Belgium (F.W.O.-Vlaanderen) to S Boonen.

\section{References}

1 Birkenhäger JC \& Bouillon R. Asymptomatic primary hyperparathyroidism. Postgraduate Medical Journal 199672 323-326.

2 Bilezikian J. Primary hyperparathyroidism. In Primer on the Metabolic Bone Diseases and Disorders of Mineral Metabolism, (4th edn), pp 187-192. Ed. M Favus. Philadelphia: Lippincott Williams \& Wilkins, 1999.

3 Bilezikian J, Potts J Jr, El-Hajj Fuleihan G, Kleerekoper M, Neer R, Peacock M, Rastad J, Silverberg SJ, Udelsman R \& Wells SA Jr. Summary statement from a workshop on asymptomatic primary hyperparathyroidism: a perspective for the 21 st century. Journal of Bone and Mineral Research 200217 (Suppl 2) N2-N11.

4 Brown M. The pathophysiology of primary hyperparathyroidism. Journal of Bone and Mineral Research 200217 (Suppl 2) N24-N29.

5 Silverberg SJ \& Bilezikian JP. Evaluation and management of primary hyperparathyroidism. Journal of Clinical Endocrinology and Metabolism 199681 2036-2083. 
6 Pearson MW. Asymptomatic primary hyperparathyroidism in the elderly - a review. Age and Ageing $1984131-5$.

7 Christiansen P, Steiniche T, Mosekilde L, Hessov I \& Melsen F. Primary hyperparathyroidism: iliac crest trabecular bone volume, structure, remodeling and balance evaluated by histomorphometric methods. Bone 199213 41-49.

8 Silverberg SJ, Gartenberg E, Jacobs TP, Shane E, Siris E, Staron RB, McMahon DJ \& Bilezikian JP. Increased bone density after parathyroidectomy in primary hyperparathyroidism. Journal of Clinical Endocrinology and Metabolism $199580729-734$.

9 Silverberg SJ, Gartenberg F, Jacobs TP, Shane E, Siris E, Staron RB \& Bilezikian JP. Longitudinal measurements of bone density and biochemical indices in untreated primary hyperparathyroidism. Journal of Clinical Endocrinology and Metabolism $199580723-728$.

10 Wilson RJ, Rao DS, Ellis B, Kleerekoper M \& Parfitt AM. Mild asymptomatic primary hyperparathyroidism is not a risk factor for vertebral fractures. Annals of Internal Medicine 1988109 959-962.

11 Melton LJ, Atkinson EJ, O'Falon M \& Heath H. Risk of age-related fractures in patients with primary hyperparathyroidism. Archives of Internal Medicine 1992152 2269-2273.

12 Larsson K, Ljunghall S, Krusemo UB, Naessen T, Lindh E \& Persson I. The risk of hip fractures in patients with primary hyperparathyroidism: a population-based cohort study with a follow-up of 19 years. Journal of Internal Medicine 1993234 585-593.

13 Kochersberger G, Buckley NJ, Leight GS, Martinez S, Studenski S, Vogler J \& Lyles KW. What is the clinical significance of bone loss in primary hyperparathyroidism? Archives of Internal Medicine $19871471951-1953$.

14 Kenny AM, MacGillivray DC, Pilbeam CC \& Crombie HD. Fracture incidence in postmenopausal women with primary hyperparathyroidism. Surgery $1995 \mathbf{1 1 8} 109-114$.

15 Khosla S, Melton LJ, Wermers RA, Crowson CS, O'Fallon WM \& Riggs BL. Primary hyperparathyroidism and the risk of fracture: a population-based study. Journal of Bone and Mineral Research 199914 1700-1707.

16 Silverberg SJ, Shane E, Jacobs TP, Siris ES, Gartenberg F, Seldin D, Clemens TL \& Bilezikian JP. Nephrolithiasis and bone involvement in primary hyperparathyroidism. American Journal of Medicine $199089327-333$.

17 Turken SA, Cafferty M \& Silverberg SJ. Neuromuscular involvement in mild, asymptomatic primary hyperparathyroidism. American Journal of Medicine 198987 553-557.

18 Kleerekoper M \& Bilezikian JP. Parathyroidectomy for non-traditional features of primary hyperparathyroidism. American Journal of Medicine 199496 99-100.

19 Lind L, Jacobson S, Palmer M, Lithell H, Wengle B \& Ljunghall S. Cardiovascular risk factors in primary hyperparathyroidism: a 15-year follow-up of operated and nonoperated cases. Journal of Internal Medicine $199123029-35$.

20 Consensus Development Conference Panel, Diagnosis and management of asymptomatic primary hyperparathyroidism: Consensus Development Conference Statement. Annals of Internal Medicine 1991114 593-597.

21 Silverberg SJ, Bilezikian JP, Bone HG, Talpos GB, Horwitz MJ \& Stewart AF. Therapeutic controversies in primary hyperparathyroidism. Journal of Clinical Endocrinology and Metabolism 199984 2275-2278.

22 Kanis J. Assessment of fracture risk and its application to screening for postmenopausal osteoporosis: synopsis of a WHO report. Osteoporosis International 19944 368-381.

23 Willeke F, Willeke M, Hinz U, Lorenz D, Nitschmann K, Grauer A, Senninger N, Klar E \& Herfarth C. Effect of surgeon expertise on the outcome in primary hyperparathyroidism. Archives of Surgery $19981331066-1077$.

24 Irvin GL, Sfakianakis G, Yeung L, Deriso GT, Fishman LM, Molinari AS \& Foss JN. Ambulatory parathyroidectomy for primary hyperparathyroidism. Archives of Surgery 1996131 1074-1078.

25 Lloyd MNH, Lees WR \& Milroy EJG. Pre-operative localisation in primary hyperparathyroidism. Clinical Radiology $1990 \quad \mathbf{4 1}$ 239-243.
26 Coakley AJ. Parathyroid aging. Nuclear Medicine Communications $199516522-533$.

27 Lundgren EC, Gillott AR, Wiseman JS \& Beck J. The role of preoperative localization in primary hyperparathyroidism. American Surgeon $199561393-396$.

28 Robertson GS, Johnson PR, Iqbal SJ \& Bell PR. Long-term results of unilateral neck exploration for preoperatively localized nonfamilial parathyroid adenomas. American Journal of Surgery 1996 $172311-314$.

29 Ryan JA, Eisenberg B, Pado KM \& Lee F. Efficacy of selective unilateral exploration in hyperparathyroidism based on localization tests. Archives of Surgery 1997132 886-891.

30 Chou F-F, Wang P-W \& Sheen-Chen S-M. Preoperative localisation of parathyroid glands in primary hyperparathyroidism. European Journal of Surgery 1997163 889-895.

31 Turton DB \& Miller DL. Recent advances in parathyroid imaging. Trends in Endocrinology and Metabolism 19967 163-168.

32 Johnston LB, Carrol MJ \& Britton KE. The accuracy of parathyroid gland localization in primary hyperparathyroidism using sestamibi radionuclides imaging. Journal of Clinical Endocrinology and Metabolism 199681 346-352.

33 Pattou F, Huglo D \& Proye C. Radionuclide scanning in parathyroid diseases. British Journal of Surgery $1998 \mathbf{8 5}$ 1605-1616.

34 Weinberger MS \& Robbins T. Diagnostic localization studies for primary hyperparathyroidism. Archives of Otolaryngology - Head and Neck Surgery $19941201187-1189$.

35 Arkles LB, Jones T, Hicks RJ, De Luise MA \& Chou ST. Impact of complementary parathyroid scintigraphy and ultrasonography on the surgical management of hyperparathyroidism. Surgery $1996120845-851$.

36 Chen CC, Molder LE, Siovill WA, Tehan AM \& Gann DS. Comparison of parathyroid imaging with technetium- $99^{\mathrm{m}}$-sestamibi and technetium-9 $9^{\mathrm{m}}$-SPECT. Journal of Nuclear Medicine $1997 \mathbf{3 8}$ 637-640.

37 Low RA \& Katz AD. Parathyroidectomy via bilateral cervical exploration: a retrospective review of 866 cases. Head and Neck $199820583-587$

38 Roe SM, Brown PW, Pate LM, Summitt JB, Ciraulo DL \& Burns RP. Initial cervical exploration for parathyroidectomy is not benefited by preoperative localization studies. American Surgeon $1998 \mathbf{6 4}$ 503-508.

39 McIntyre RC \& Ridgway EC. Sestamibi: opening a new era of parathyroid surgical procedures. Endocrine Practice 1998 4 241-244.

40 Steiniche T, Christiansen P, Vesterly A, Ullerup R, Hessov I, Mosekilde LE \& Melsen F. Primary hyperparathyroidism: bone structure, balance and remodeling before and 3 years after surgical treatment. Bone 200026 535-543.

41 Silverberg SJ, Shane E, Jacobs TP, Siris E \& Bilezikian JP. A 10-year prospective study of primary hyperparathyroidism with or without parathyroid surgery. New England Journal of Medicine 1999 341 1249-1255.

42 Gonnelli S, Montagnani A, Cepollaro C, Monaco R, Gennari L, Rossi B, Pacini S \& Gennari C. Quantitative ultrasound and bone mineral density in patients with primary hyperparathyroidism before and after surgical treatment. Osteoporosis International $200011255-260$

43 Vestergaard P, Mollerup C, Frøkjaer V, Christiansen P, BlichertTopt M \& Mosekilde L. Cohort study of risk of fracture before and after surgery for primary hyperparthyroidism. British Medical Journal $2000321598-602$.

44 Christiansen P, Steiniche T, Mosekilde L, Hessov I \& Melsen F. Primary hyperparathyroidism: changes in trabecular bone remodeling following surgical treatment - evaluated by histomorphometric methods. Bone 19901 75-79.

45 Reeve J, Meunier PJ, Parsons JA, Bernat M, Bijvoet OL, Courpron P, Edouard C, Klenerman L, Neer RM, Renier JC, Slovik D, Vismans FJ \& Potts JT Jr. Anabolic effects of human parathyroid hormone fragment on trabecular bone in involutional osteoporosis: a multicentre trial. British Medical Journal 1980280 1340-1344. 
46 Lindsay R, Nieves J, Formica C, Henneman E, Woelfert L, Shen V, Dempster D \& Cosman F. Randomised controlled study of effect of parathyroid hormone on vertebral-bone mass and fracture incidence among postmenopausal women on oestrogen with osteoporosis. Lancet $1997350550-555$.

47 Bilezikian JP. Management of hypercalcemia. Journal of Clinical Endocrinology and Metabolism 199377 1445-1449.

48 Locker FG, Silverberg SJ \& Bilezikian JP. Optimal dietary calcium intake in primary hyperparathyroidism. American Journal of Medicine 1997102 543-550.

49 Parfitt AM. Hormonal influences on bone remodeling and bone loss: application to the management of primary hyperparathyroidism. Annals of Internal Medicine 1996125 413-415.

50 Grey AB, Stapleton JP, Evans MC, Tatnell MA \& Reid IR. Effect of hormone replacement therapy on bone mineral density in postmenopausal women with mild primary hyperparathyroidism. A randomized, controlled trial. Annals of Internal Medicine 1996 $125360-368$.

51 Kaplan RA, Geho WB, Poindexter C, Maussler M, Dietz GW \& Pal CYC. Metabolic effects of diphosphonate in primary hyperparathyroidism. Journal of Clinical Pharmacology 197717 410-419.

52 Douglas OL, Kanis JA, Paterson AD, Beard DJ, Cameron EC, Watson ME, Woodhead S, Williams J \& Russell RG. Drug treatment of primary hyperparathyroidism: use of clodronate disodium. British Medical Journal $1983286587-589$.

53 Reasner CA, Stone MD, Hosking DJ, Ballah A \& Mundy GR. Acute changes in calcium homeostasis during treatment of primary hyperparathyroidism with risedronate. Journal of Clinical Endocrinology and Metabolism 199377 1067-1071.

54 Parker CR, Blackwell PJ, Fairbairn KJ \& Rosking DJ. Alendronate in the treatment of primary hyperparathyroid-related osteoporosis: a 2-year study. Journal of Clinical Endocrinology and Metabolism $2002874482-4489$.

55 Chow CC, Chan WB, Li JK, Chan NN, Chan MH, Ko GT, Lo KW \& Cockram CS. Oral alendronate increases bone mineral density in postmenopausal women with primary hyperparathyroidism. Journal of Clinical Endocrinology and Metabolism $2003 \mathbf{8 8}$ $581-587$.

56 Silverberg SJ, Bone HG, Marriott TB, Locker FG, Thys-Jacobs S, Dziem G, Kaatz S, Sanguinetti EL \& Bilezikian JP. Short-term inhibition of parathyroid hormone secretion by a calcium-receptor agonist in patients with primary hyperparathyroidism. New England Journal of Medicine 1997337 1506-1510.

57 Lafferty FW \& Hubay CA. Primary hyperparathyroidism. A review of long-term surgical and nonsurgical morbidities as a basis for a rational approach to treatment. Archives of Internal Medicine 1989 $149789-796$

58 Wermers RA, Khosla S, Atkinson EJ, Grant CS, Hodgson SF, O'Fallon WM \& Melton LJ 3rd. Survival after the diagnosis of hyperparathyroidism: a population based study. American Journal of Medicine $1998 \mathbf{1 0 4} 115-122$.

59 Silverberg SJ, Shane E \& de la Cruz L. Skeletal disease in primary hyperparathyroidism. Journal of Bone and Mineral Research 19894 283-291.

60 Sosa JA, Powe NR, Levine MA, Bowman HM, Zeiger MA \& Udelsman R. Cost implications of different surgical management strategies for primary hyperparathyroidism. Surgery $1998 \mathbf{1 2 4}$ $1028-1036$.

61 Sosa JA, Powe NR, Levine MA, Udelsman R \& Zeiger MA. Thresholds for surgery and surgical outcomes for patients with primary hyperparathyroidism: a national survey of endocrine surgeons. Journal of Clinical Endocrinology and Metabolism $1998 \mathbf{8 3}$ 2658-2662.

62 Ohrwall U, Akerstrom G, Ljunghall S, Lundgren E, Juhlin C \& Rastad J. Surgery for sporadic primary hyperparathyroidism in the elderly. World Journal of Surgery $1994 \mathbf{1 8} 612-618$.

63 Hedbach G, Oden A \& Tisell LE. The influence of surgery on the risk of death in patients with primary hyperparathyroidism. World Journal of Surgery 199115 399-405.

64 Deftos LJ, Partemore JG \& Stabile BE. Management of primary hyperparathyroidism. Annual Review of Medicine 1993 44 19-26.

65 Uden P, Chan A, Duh Q-Y, Siperstein A \& Clark OH. Primary hyperparathyroidism in younger and older patients: symptoms and outcome of surgery. World Journal of Surgery 199216 $791-798$.

66 de Groen PC, Lubbe DF, Hirsch LJ, Daifotis A, Stephenson W, Freedholm D, Pryor-Tillotson S, Seleznick MJ, Pinkas H \& Wang K. Esophagitis associated with the use of alendronate. New England Journal of Medicine 1996335 1016-1021.

67 Boonen S, McClung M, Eastell R, Fuleihan G, Barton I \& Delmas P. Safety and efficacy of risedronate in reducing fracture risk in osteoporotic women 80 years of age or older: implications for the use of antiresorptive agents in the old and oldest old. Journal of the American Geriatrics Society (In Press).

Received 6 April 2004

Accepted 24 May 2004 